\title{
Enhanced Assessment System to Improve The Efficiency of Current Generation Students
}

\author{
N.Jayakanthan, D. Sowmiya
}

\begin{abstract}
Assessment leads to learning. The present generation students properly guided in their learning. The correct assessment improves the learning of the students. In the paper we present a new assessment model "E-Brahma" to assess the performance of the students in current academic scenario and it also enhance the learning system also. In this paper we propose an assessment algorithm. The experimental results show the efficiency of the proposed system.

Keywords: Online Assessment, E-Bramaha, Assessment, Grading.
\end{abstract}

\section{INTRODUCTION}

The efficiency of academia is a important factor in the present scenario. Now days the students are from the different geographical location with diffract background and characteristics. It is essential to understand the students and their character, attitude, aptitude and skill before assessing them. The students to be guided properly before improving the performance.

In the current academic scenario it is essential to prepare the students as a employable candidates. The students to be profiled sharply, their skills need to be enhanced and finally they are guided to achieve their dream placement.

The students profiling is a science. It is essential to understand the students to profile and assessing them. The purpose of the assessment is to enhance the skill levels of the students. The assessment includes various policies, procedure, methods, practices and software's to conduct the assessment. The effective assessment should provide the qualitative and quantitative information to support the assessor to come for the conclusion.All the world wide institutions now focusing on improving the assessment system.

This paper proposes a multi-scale assessment system. Every scale is used to assess the particular aspect of the students. Like character, attitude, Aptitude, Technical skills and Cognitive skills. Finally the assessment is used to help the students to improve the performance.

The rest of the chapter organizes as follows chapter 2 provide literature survey, chapter 3 represent the algorithms and analysis of the result is given in the chapter 4 . Chapter 5 concludes the research work.

Revised Manuscript Received on August 14, 2019.

N. Jayakanthan, Assistant Professor(SRG), Department of Computer Applications, Kumaraguru College of Technology, Coimbatore. T.N, India. (E-mail: jayakanthan.n.mca@kct.ac.in)

D. Sowmiya, Department of Computer Applications, Kumaraguru College of Technology, Coimbatore. T.N, India. (E-mail: sowmiya.16mca@kct.ac.in)

\section{LITERATURE SURVEY}

Ahmad Taherkhani[1] proposed a dynamic algorithm to automate the assessment process. It is a quick sort based non recursive algorithm. It is a knowledge based approach and the experiment results proves the efficiency.

Ying $\mathrm{Yu}$ [2] proposed a student assessment system for distance learning students. The system is used for online assessment for colleges and universities. A simulative academic assessment environment is suggested.

N.Jayakanthan et al[3] discuss the various issues in online system. This points are very useful in developing an online assessment system.

N.Jayakanthan [4] et al discusses the various attacks in online system. Hence developing an online assessment system includes appropriate security measures. The suggest prevention activities are useful developing a e-grading system for the students.

Tatiana Melguizo et al [5] analyze the various research and innovations in higher education. This paper instits the values of academic system should reflect in students learning outcomes.

AdiLevy-VeredaFadia[6] discussed about the basics of assessment. They discuss the various aspects of assessment and their impacts in the present scenario.

Sarah R. Gordon et al[7] analyze the inter cultural senility of the american student. Their behaviors based on religion, traveling outside abroad. This research provide the theory based evaluation in educational system.

Zohre Mohamadi [8] analyzes the comparative effort of summative and formative assessment on EFT (English as a Foreign Language Students) writing ability. The writing performances were assessed using International English Language Testing System (IELTS) rating scale. The experimental result shows the efficiency of the system.

\section{METHODOLOGY}

It is responsibility of the teacher and academic institutions to produce the students as employable. Hence this paper proposes a model called E-brama. It assesses the performance and enhances the efficiency of the students.

The algorithm student assessment marker checks the nativity of the student whether he belongs to rural or urban. Then checks his answer script. In this answer script it analyzes the technical session. Based on the performance it

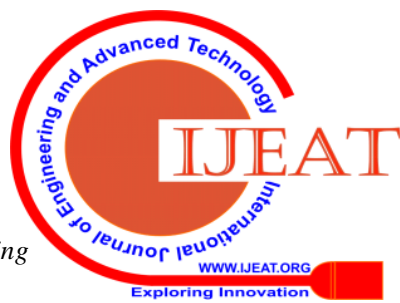


marks it under the five scales- Poor, Satisfactory, and Good \& Efficient. After that the grammatical session is analyzed. Followed by aptitude, technical and grades obtained in the various subjects. This algorithm uses the personal analyzer algorithm and finally displays the grading, ranking and suggestion for improvement.

The personal analyzer algorithm analyzes the profile of the student followed by category, class room behaviour, regularity and personal detail. This algorithm marks the personal character under the same five scale section. It provides the personal score to the student assessment marker algorithm.

\section{Algorithm}

\section{Algorithm Student Assessment Marker}

Input : The Category \& Assessment questions

Output : The grading \& Suggestion for improvement

1. Check the student belong to Rural or Urban

2. Check the Answer script

3. Analyze the Technical section and categorize him under Poor, Satisfactory, Good or Efficient

4. Analyze the grammatical section mark him under appropriate classes

5. Check the aptitude section mark him in specific classes

6. Assess the technical session assign them is concerned classes

7. Calculate the grading and analyze the ranking with relative Grading

8. Call the Character Analyzer algorithm and obtain the Personal detail

9. Display the grading, ranking \& suggestion to Improvement.

\section{Algorithm-II Personal character Analyzer:}

1. Select the profile of the student

2. Categorize the location of the student

3. Assess the class room behaviour $\mathrm{E}_{\mathrm{T}}$

4. Find the regularity of the students

5. Analyze the behavioural issue

6. Return the Personal detail

The above algorithm analyzes the personal and behavioural characteristics of the student.

\begin{tabular}{|l|l|c|c|c|}
\hline \multirow{2}{*}{ Dimension } & Poor & Satisfactory & Good & Efficient \\
\hline & & & & \\
\hline Attitude & & $\checkmark$ & & \\
\hline Grammar & & & $\checkmark$ & \\
\hline Aptitude & & $\checkmark$ & & \\
\hline Technical & & & & $\checkmark$ \\
\hline Grading & & & $\checkmark$ & \\
\hline
\end{tabular}

Table 1 :Sample Performance Analysis

Table 1 reports the sample performance analyzer. The tick mark represents the mark of the students in appropriate category. The five dimension attitude, grammar, aptitude, technical and grading are marked under four scales. Poor, Satisfactory, Good and efficient.

\begin{tabular}{|l|l|c|c|c|}
\hline \multirow{2}{*}{ Dimension } & Poor & Satisfactory & Good & Efficient \\
\hline & & & & \\
\hline Attitude & & $\checkmark$ & & \\
\hline Grammar & & & $\checkmark$ & \\
\hline Aptitude & & $\checkmark$ & & \\
\hline Technical & & & & $\checkmark$ \\
\hline Grading & & & $\checkmark$ & \\
\hline
\end{tabular}

Table 2 : Sample Character Analysis

In the grading the poor is marked as value 1, Satisfactory2,Good-3 and Efficient-4. Which is similar to personal attitude table? If the scale values greater than 3.5 then students performance is satisfactory otherwise he needs to be improved along with this score the feedback also given to the students.

\section{IMPLEMENTATION AND EVALUATION RESULTS}

The proposed method has implemented as a separate classes of a Java project. In phase-I the student assessment marker algorithm analyze the various input parameters like attitude, grammar, aptitude and technical skills. It analyze the personal characters with the help of personal character analyzer algorithm. The real time data are collected from various classes as sampling. Few of the synthesized data are used. Distinct data set is used for training and testing to improve the efficiency.

The following figure shows the discrepancies in student's characteristics.

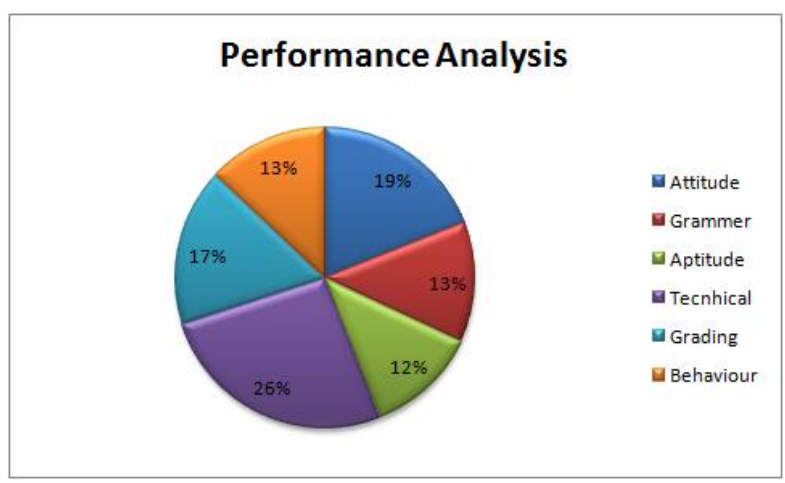

Figure 1. Performance Analysis

The figure 1 shows the performance analysis of the proposed algorithm. A data set of the size 600 students is analyzed. Most of students are weakness in technical skills in total $26 \%$. Attitude 19\%, Grammar 13\%, Aptitude 12\%, Grading $17 \%$ and behavioral issue $13 \%$. Hence the system is helpful in analyzing various aspects of the students and efficiently reporting the performance. 


\section{CONCLUSION:}

The performance enhancement of the students is the primary responsibility of the academic institution. So it is essential to constantly assess the performance and suggest improves to the students to make students employable. Hence this paper proposes a tool E-Bramma which assess the students attitude, grammar, aptitude, Technical, Grading and the behavior. Based on the assessment the score and suggestion for improvement are given to the students. The tool is tested with a data set of size 600 students. The experiment result shows the efficiency of the proposed system.

\section{REFERENCES}

1. Ahmad Taherkhani, Algorithm Recognition by Static Analysis and Its Application in Students' Submissions Assessment, Koli Calling '08 November 13-16, 2008, Koli, Finland. pp.88-91.

2. Ying Yu, Student Assessment System for Distance Education on Financial Management, Vol. 11, Issue 10, (International Journal of Engineering and Technology.

3. N.Jayakanthan, M.Manikantan and R.Viveak, "The enhanced learning model to improve the quality of E-shopping and stock management", International Journal of Pure and Applied Mathematics, Vol. 115, No. 2, 2018, pp. 837-841

4. N.Jayakanthan and M.Manikantan, "Malicious Attack Detector", International Journal of Advance Research and Innovative Ideas in Education, Vol.3, Issue 1, 2017.

5. Tatiana Melgizo and Hamish Coates, The Value of Assessing Higher Education Student Learning Outcomes,AERA Open Journal, Vol. 3, No. 3, pp.1-2, 2017

6. AdiLevy-VeredaFadia and Nasser-AbuAlhija, "The power of a basic assessment course in changing preservice teachers' conceptions of assessment, Studies in Educational Evaluation" Vol. 59, pp. 84-93 December 2018.

7. Sarah R. Gordon and Mwarumba Mwavita, "Evaluating the International Dimension in an Undergraduate Curriculum by assessing students Intercultural sensitivity", Studies in Educational Evaluation, Vol. 59, pp. 76-83, 2018.

8. ZohreMohamadi, Comparative Effect of Online Summative and Formative Assessment on EFL Student Writing Ability, Studies in Educational Evaluation Vol. 59, pp.29-40, 